\title{
A rare case: Covid-19 infection diagnosed by transthoracic fine needle aspiration biopsy
}

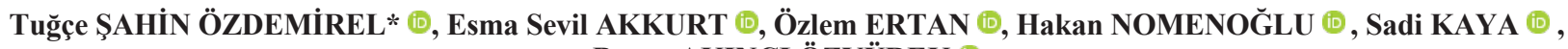
Berna AKINCI ÖZYÜREK (i)

Department of Chest Diseases, Health Sciences University, Atatürk Chest Diseases and Chest Surgery Training and Research Hospital, Ankara, Turkey

\begin{tabular}{l} 
Received: $11.03 .2021 \quad$ Accepted/Published Online: 30.03 .2021 \\
\hline Abstract \\
Covid 19 is an acute respiratory disease caused by a novel type of Coronavirus (SARS-CoV-2) that was first detected in Wuhan, Hubei Province \\
of China. Its most common symptoms are fever, cough, and weakness; and in the early stages, there may not be findings on chest computed \\
tomography. In pulmonary involvement, peripheral ground-glass areas, a cobblestone appearance, consolidated areas, and interlobular septal \\
thickening, which are usually prominent in the lower lobes may be seen in thorax computed tomography. Consolidation, solid nodules, halo \\
sign, inverted halo sign, vascular enlargement, subpleural line, air bronchograms, and bronchiectasis are other less common findings. In our \\
case, we aimed to present our 69 years old female patient with bilateral nodular densities on thoracic CT and transthoracic fine-needle aspiration \\
biopsy result was reported as lesions compatible with interstitial fibrosis due to Covid-19 inflammation.
\end{tabular}

Keywords: Covid-19, interstitial fibrosis, nodule, thorax computed tomography, transthoracic fine needle aspiration biopsy

\section{Introduction}

Covid 19 is an acute respiratory disease caused by a novel type of Coronavirus (SARS-CoV-2) that was first detected in Wuhan, Hubei Province of China. Its most common symptoms are fever, cough, and weakness; and in the early stages, there may not be findings on chest computed tomography (1). In pulmonary involvement, peripheral ground-glass areas, a cobblestone appearance, consolidated areas, and interlobular septal thickening, which are usually prominent in the lower lobes may be seen in thorax computed tomography (2). Consolidation, solid nodules, halo sign, inverted halo sign, vascular enlargement, subpleural line, air bronchograms, and bronchiectasis are other less common findings (3).

For the diagnosis of Covid-19, the real-time reverse transcription-polymerase chain reaction (RT-PCR) of viral nucleic acid is accepted as the reference standard, however, thoracic CT examination is important in Covid-19 patients with false-negative RT-PCR results, and recent studies have reported the CT sensitivity as $98 \%$ (4-6).

In our case, we aimed to present our female patient who had bilateral nodular densities on thoracic CT and transthoracic fine-needle aspiration biopsy (TTFNAB) was reported as lesions compatible with interstitial fibrosis due to Covid-19 inflammation.

\section{Case report}

The sixty-nine-year-old female patient attended an external center with the complaint of cough and tested negative for Covid PCR test. Positron emission tomography / computed tomography (PET/CT) was performed due to the presence of the bilateral consolidated, solid nodular appearance in the thorax CT of the patient (Fig. 1), whose Covid PCR test was negative twice. In PET/CT; low-moderate increased metabolic activity involvement (left SUVmax: 4.94, right SUVmax: 3.58 ) in bilateral lower paratracheal, subcarinal and bilateral hilar lymph nodes in the mediastinum, subsegmental collapse/consolidation areas showing nodularity in both lungs especially in the basal area, nodular-reticulonodular densities of maximum $2 \mathrm{~cm}$ in size again in both lungs, and pathologically increased metabolic activity involvements (SUVmax: 7.36) were observed. The TTFNAB performed with a pre-diagnosis of malignancy was reported as "Lung parenchyma compatible with fibrosis that develops after Covid-19 inflammation". Covid PCR sample of the patient, taken for the third time was detected positive and favipiravir treatment was initiated. The patient was transferred to our service for further examination and treatment. In the chest radiography of the patient, there were bilateral nodular infiltrations (Fig. 1). Her saturation at room air was $96 \%$. The laboratory findings were reported as; the leukocyte count: $7300 \mu \mathrm{L}$, ferritin value: $432 \mathrm{ng} / \mathrm{ml}$, D-dimer: $0.62 \mathrm{mg} / \mathrm{L}$, 
lymphocyte count: $1450 \mu \mathrm{L}$, C-reactive protein (CRP): 75 $\mathrm{mg} / \mathrm{L}$, Troponin: $14.4 \mathrm{ng} / \mathrm{L}$. In addition to favipiravir treatment, methylprednisolone $40 \mathrm{mg}$, a prophylactic dose of low molecular weight heparin, and broad-spectrum antibiotic treatment were initiated in the patient who previously used empirical antibiotics. During the follow-up of the patient, hypoxia developed on the $7^{\text {th }}$ day of hospitalization and Covid PCR positivity. The patient was provided oxygen support with a mask with a reservoir, whose saturation value was below $90 \%$ despite the $10 \mathrm{~L} / \mathrm{min}$ oxygen therapy with a nasal cannula. Progression was observed in bilateral infiltrations on chest radiography. The laboratory values of the patient were CRP: $180 \mathrm{mg} / \mathrm{L}$, ferritin: $1650 \mathrm{ng} / \mathrm{ml}$, D-dimer: $2.19 \mathrm{mg} / \mathrm{L}$, as lymphocyte count: $510 \mu \mathrm{L}$. The patient was considered to have entered a cytokine storm, and $250 \mathrm{mg}$ methylprednisolone pulse therapy was administered for three days. The patient, who also developed bilateral hearing loss, was consulted to the Neurology Department.
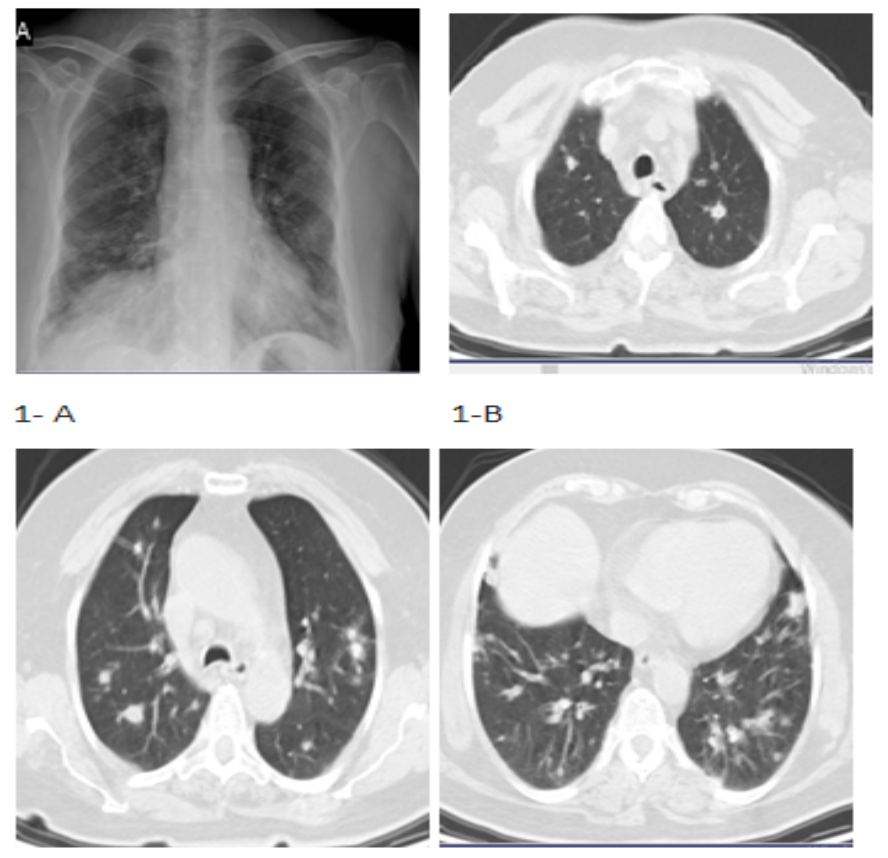

1-B

1- C

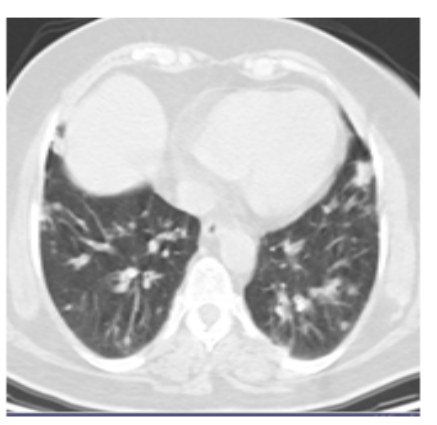

$1-\mathrm{D}$

Fig. 1. A: Initial chest X- ray; bilateral nodular lesions. B: Thorax computed tomography $(\mathrm{CT})$, bilateral nodular lesions at upper lobes of lungs. C: Thorax CT, bilateral nodular lesions at upper and middle zones of lungs. D: Thorax CT, bilateral nodular lesions at lower lobes of lungs

Neurological pathology was not detected patient. The patient was consulted to the otorhinolaryngology department and hearing loss was thought to be due to serous otitis which was secondary to Covid-19. Continuing the steroid therapy was recommended. Clinical improvement was observed in the follow-up. Oxygen saturation in room air increased to $96 \%$. Regression was observed in the lesions on chest radiography. Steroid therapy was tapered and ended. The patient was discharged with full recovery. On the control visit, it was learned that the hearing loss improved. The patient was recommended for clinical and radiological follow-up.

\section{Discussion}

The Covid-19 pandemic, which started in China in December 2019 and spread all over the world, is a serious health problem today that concerns all countries (7). In the course of the disease, although fever and cough are the first common signs, cases with nonspecific findings such as weakness, loss of appetite, muscle pain, diarrhea, nausea, vomiting, abdominal pain, and headache are also reported (8). In our case, there was no fever, but weakness and cough complaints were present.

In the literature, the presence of ground-glass opacities with or without consolidation in bilateral, peripheral, and posterior areas on thoracic $\mathrm{CT}$ in the lungs has been identified as the most important feature of Covid-19. However, it was observed that there were also findings such as a cobblestone view, airway changes, and inverted halo sign in further and more investigations made with the increased number of cases. $(9,10)$. It has been stated in the literature that multifocal, solid, irregularly circumscribed nodular structures in thorax $\mathrm{CT}$ are one of the findings were seen in viral pneumonia cases, which can also be seen in $3-13 \%$ of Covid-19 cases which are accompanied by minimal ground glass appearance around them (11-13).

In our case, there were bilateral solid nodular appearances on thorax CT. The possibility of the presence of lymphadenopathy (LAP) larger than $1 \mathrm{~cm}$ is $4-8 \%$ and it is generally an unexpected finding, and it may be seen in serious cases. It has been reported that $17 \%$ of patients healed with fibrotic bands, which was considered as a good prognosis because of being stable disease finding and could indicate a poor prognosis for the risk of development of fibrotic lung disease in the future (11). Pulmonary nodules can be encountered in many clinical conditions, from infections to malignancies, and lung tissue biopsy is needed for differential diagnosis. PET/CT is useful in the differentiation of benign pulmonary nodules and malignant nodules. TTFNAB is usually the first preferred interventional procedure in the evaluation of peripheral lesions suspected of being malignant.

In our case, TTFNAB was performed due to the presence of mediastinal lymphadenopathies and high bilateral nodular SUVmax values in PET/CT performed with a pre-diagnosis of malignancy; and the pathology was reported as lung tissue compatible with fibrosis after Covid-19 pneumonia. In the literature, the mainly reported pathological findings are diffuse alveolar damage, organized pneumonia, reactive type II pneumocytes, and chronic interstitial pneumonia $(14,15)$. In the pathology report of our patient, it was stated that interstitial fibrosis was detected, which could be due to Covid -19. It was seen that the chest radiography of the patient was normal in the previous radiological images from the records and this new situation was believed to develop due to Covid19.

In the literature, it has been stated that otitis findings may 
be the first sign for Covid-19 infection in some cases, and case series are reported (16). In our case, the hearing loss that developed while our patient was receiving Covid-19 pneumonia treatment was thought to be due to, serous otitis, a complication of Covid-19.

Covid 19 continues to manifest itself with different clinical and radiological findings every day and threaten the whole world. Although bilateral solid nodular consolidations are not common in Covid-19, it should be kept in mind in differential diagnosis despite the negatively detected Covid PCR.

\section{Conflict of interest}

We declare that there is no conflict of interest, in particular no financial funding potentially relevant to the contents of manuscript.

\section{Acknowledgments}

All support for this study came from institutional and departmental resources.

\section{References}

1. Wong H, Lam H, Fong AH, Leung ST, Chin TW, Lo C, et al. Frequency and Distribution of Chest Radiographic Findings in COVID-19 Positive Patients. Radiology. 2020;201160.

2. Pekcevik Y, Belet U. Patient Management in the Radiology Department, the Role of Chest Imaging During the SARS-CoV-2 Pandemic and Chest CT Findings Related to COVID-19 Pneumonia. The journal of Tepecik Education and Research Hospital. 2020;30(2): 195-212.

3. Çinkooğlu A, Hepdurgun C, Bayraktaroğlu S, Ceylan N, Savaş R. CT imaging features of COVID-19 pneumonia: Initial experience from Turkey. Diagn Interv Radiol. 2020;26(4):308314.

4. Xie X, Zhong Z, Zhao W, Zheng C, Wang F, Liu J. Chest CT for typical 2019-nCoV pneumonia: relationship to negative RT-PCR testing. 2020; 296(2):41-45.

5. Huang $P$, Liu $T$, Huang $L$, Liu $H$, Lei $M, X u ~ W$, et al. Use of Chest CT in Combination with Negative RT-PCR Assay for the
2019 Novel Coronavirus but High Clinical Suspicion. Radiology. 2020;295(1):22-23.

6. Fang Y, Zhang H, Xie J, Lin M, Ying L, Pang P, et al. Sensitivity of chest CT for COVID-19: comparison to RT-PCR. Radiology. 2020;296(2): E115-E117.

7. World Health Organization. Director-General's remarks at the media briefing on 2019-nCoV on 11 February 2020.

8. Wang $\mathrm{D}, \mathrm{Hu} \mathrm{B}, \mathrm{Hu} \mathrm{C}$, Zhu F, Liu X, Zhang J, et al. Clinical Characteristics of 138 Hospitalized Patients With 2019 Novel Coronavirus-Infected Pneumonia in Wuhan, China. JAMA. 2020; 323:1061-10699.

9. Chung M, Bernheim A, Mei X, Zhang N, Huang M, Zeng X, et al. CT Imaging Features of 2019 Novel Coronavirus (2019nCoV) Radiology. 2020;295(1):202-207.

10. Fang Y, Zhang H, Xu Y, Xie J, Pang P, Ji W, et al. CT Manifestations of Two Cases of 2019 Novel Coronavirus (2019nCoV) Pneumonia. Radiology. 2020;295(1):208-209.

11. Zheng Y, Yun Z, Yi W, Zixiang H, Bin S. Chest CT manifestations of new coronavirus disease 2019 (COVID-19): A pictorial review. Eur. Radiol. 2020; 30(8):4381-4389.

12. Pan Y, Guan H, Zhou S, Wang Y, Li Q, Zhu T, et al. Initial CT findings and temporal changes in patients with the novel coronavirus pneumonia (2019-nCoV): a study of 63 patients in Wuhan, China. Eur Radiol. 2020;30(6):3306-3309.

13. Ai T, Yang Z, Hou H, Zhan C, Chen C, Lv W, et al. Correlation of chest CT and RT-PCR testing in coronavirus disease 2019 (COVID-19) in China: a report of 1014 cases. Radiology. 2020; 296(2): E32-E40.

14. Zhang $\mathrm{H}$, Zhou $\mathrm{P}$, Wei $\mathrm{Y}$, Yue $\mathrm{H}$, Wang $\mathrm{Y}$, $\mathrm{Hu} \mathrm{M}$, et al. Histopathologic changes and SARS-CoV-2 Immunostaining in the lung of a patient with COVID-19. Ann Intern Med. 2020; 172:629-632.

15. Pernazza A, Mancini M, Rullo E, Bassi M, De Giacomo T, Rocca CD, et al. Early histologic findings of pulmonary SARSCoV-2 infection detected in a surgical specimen. Virchows Arch. 2020;477(5):743-748. doi: 10.1007/s00428-020-02829-1.

16. Raad N, Ghorbani J, Mikaniki N, Haseli S, Karimi-Galougahi M. Otitis media in coronavirus disease 2019: A case series. J Laryngol Otol. 2021; 7:1-4. 